\title{
VALIDATION OF A LIQUID CHROMATOGRAPHY-FLUORESCENCE SPECTROMETRIC METHOD FOR THE QUANTIFICATION OF FOUR QUINOLONES IN PIG AND CHICKEN MUSCLE FOLLOWING THE EUROPEAN UNION GUIDELINE EC/657/2002
}

\author{
Y. VASQUEZ-MARTINEZ, L. VILLEGAS R., A. VILLA AND G. MASSIFF \\ Centre for Chemical Metrology (CMQ) - Fundación Chile, Santiago; Chile \\ (Received: July 21, 2010 - Accepted: January 6, 2011)
}

\begin{abstract}
Quinolones are a group of structurally related antibacterial compounds. Over the last years their use in animal production has been greatly increased. This increase can cause the resistance of bacteria. In order to protect human health the European Union (EU), as well as other countries, has established Maximum Residue Limits (MRL) for these antibacterial agents in several foods. Among these foods, pig and chicken muscle have different MRLs in the sub-ppm range.

A liquid chromatography-fluorescence spectrometric method has been developed and validated for the simultaneous assessment of four of the most used quinolones in edible animal matrices production. Simultaneous quantification of enrofloxacin, ciprofloxacin, oxolinic acid and flumequine was achieved by a method involving an initial aqueous extraction step followed by a solid-liquid-phase extraction using reverse-phase columns (C-18) and a final injection of all quinolones in a single chromatographic run using HPLC-Fluorescence detection. Nalidixic acid was used as internal standard.

In addition to the description of the analytical method developed for the quantification of the studied quinolones, the different validation parameters of this method according to Commission Decision EC /657/2002 of the EU are presented and discussed.
\end{abstract}

Keywords: Quinolones, pig and chicken muscle, HPLC-fluorescence detection

\section{INTRODUCTION}

Quinolones are antibacterial compounds with a high activity against Grampositive and Gram-negative bacteria including those that are already resistant to $\beta$-lactames and sulphonamides antibiotics ${ }^{1}$. This group of structurally related compounds is usually divided into two categories. The first includes the compounds containing a pyridine-carboxylic acid group combined with an aromatic or heteroaromatic ring such as flumequine, oxolinic acid and nalidixic acid. These latter compounds show a moderate activity against Gramnegative bacteria. A second category includes the fluoro-quinolones, which have a fluorine atom attached to the C-6 position and a piperazynil group in the $\mathrm{C}-7$ position. Typical compounds in this second category are ciprofloxacin, enrofloxacin, and levofloxacin, which show a broad spectrum against Gramnegative, Gram-positive bacteria and mycoplasma ${ }^{2}$.

These antibacterial properties have made this group of compounds powerful agents in the treatment of animal infections ${ }^{3}$. The administration of quinolones to animals such as pigs and chicken that are produced for human consumption can result in the presence of residues in the animal tissues which, in turn, might result in a hazard for the consumer ${ }^{4}$. Specifically, reports have been published on the strong relationship between the use of quinolones in salmon production and the development of a resistance to Campylobacter jejune caused infection in humans ${ }^{5}$.

Taking into account the potential hazards that residues of quinolones in edible animal matrices can cause, international institutions such as the Japan regulatory agency (The Japan Research Chemical Foundation, MHLW), and the European Union regulatory agency (Commission of the European communities) have established Maximum Residue Limits (MRL) for these compounds. ${ }^{6,7}$

Table 1 show the MRLs for some quinolones in pig and chicken muscle established in different countries.

Table 1: Maximum allowed concentration $(\mathrm{mg} / \mathrm{kg})$ limits for four quinolones in pig and chicken muscle.

\begin{tabular}{|l|l|l|l|l|}
\hline \multicolumn{1}{|c|}{ Compound } & \multicolumn{2}{|c|}{ European Union } & \multicolumn{2}{c|}{ Japan } \\
\hline Animal matrix & $\begin{array}{l}\text { Chicken } \\
(\mathrm{mg} / \mathrm{kg})\end{array}$ & $\begin{array}{c}\mathrm{Pig} \\
(\mathrm{mg} / \mathrm{kg})\end{array}$ & $\begin{array}{c}\text { Chicken } \\
(\mathrm{mg} / \mathrm{kg})\end{array}$ & $\begin{array}{c}\text { Pig } \\
(\mathrm{mg} / \mathrm{kg})\end{array}$ \\
\hline $\begin{array}{l}\text { Ciprofloxacin } \\
+ \\
\text { Enrofloxacin }\end{array}$ & $\begin{array}{l}\text { 0.1 for the } \\
\text { sum of the } \\
\text { concentrations } \\
\text { of both } \\
\text { compounds }\end{array}$ & $\begin{array}{l}\text { Same } \\
\text { as for } \\
\text { chicken }\end{array}$ & $\begin{array}{l}\text { 0.05 for the } \\
\text { sum of the } \\
\text { concentrations } \\
\text { of both } \\
\text { compounds }\end{array}$ & $\begin{array}{l}\text { Same } \\
\text { as for } \\
\text { chicken }\end{array}$ \\
\hline Oxolinic acid & 0.1 & 0.1 & 0.03 & 0.02 \\
\hline Flumequine & 0.4 & 0.2 & 0.5 & 0.5 \\
\hline
\end{tabular}

Several detection methods such as ultraviolet (UV), fluorescence or mass spectrometry (MS) are used in combination with liquid chromatography (LC) for the determination of quinolones. Earlier methods used UV almost exclusively ${ }^{8,9}$ but more recently fluorescence detection has been preferred $\mathrm{d}^{10,11,12,13}$. On the other hand, LC with MS is also used at the international level since this technique has a higher sensitivity and selectivity and is particularly suited for multi-residue determination in complex matrices ${ }^{14,5,6,7,8}$.

The present paper reports on the analytical method based on LC with fluorescence (LC-Fl) deetection and its validation according the scheme suggested by European Union guideline EC/657/2002. However, the development of an analytical procedure based in LC-MS and its validation was also successfully carried out in our laboratory. This study will be reported elsewhere.

\section{EXPERIMENTAL}

\section{Reagents and chemicals}

The quinolone calibration standards were purchased to the Company "Dr Ehrenstorfer Gmbh" (Augsburg, Germany) and the corresponding control standards and internal standard (nalidixic acid) were obtained from Fluka (Sigma-Aldrich, St. Louis, MO, USA). All chemicals used were either HPLC grade or analytical grade from Merck (Darmstadt, Germany).

Stock standard and control solutions of $100 \mathrm{mg} \mathrm{kg}^{-1}$ were gravimetrically prepared from the high purity solid compounds in a $\mathrm{NaOH}$ in methanol $(100 \mu \mathrm{L}$ $\mathrm{NaOH}$ aqueous solution $1 \mathrm{M} / 100 \mathrm{~mL}$ ) solution. Intermediate multi-standard and control solutions $\left(2.5 \mathrm{mg} \mathrm{kg}^{-1}\right)$ were gravimetrically prepared from the stock solutions in phosphate buffer $\mathrm{pH}$ 7.4. Internal standard (nalidixic acid) solutions were prepared in a similar way.

Standard samples of the pig and chicken muscle matrices were used for the preparation of calibration curves in a concentration range $0.025-0.200 \mathrm{mg}$ $\mathrm{kg}^{-1}$. These calibration standards were prepared from pig and chicken samples purchased at a local market in Santiago (blank tissue). After the manual elimination of fat and connective tissue with the aid of a knife, a homogeneous paste (homogenate) of the edible matrices was obtained using a food processor. These samples were stored at $-20^{\circ} \mathrm{C}$ until the validation study was started. The homogenate was spiked to yield five different concentrations $(0.025-0.2 \mathrm{mg}$ $\mathrm{kg}^{-1}$ ) adding five different aliquots of the multi-standard solution. Six control samples were prepared spiking the pig and chicken homogenates with the multi-standard control solution in order to obtain a concentration value near the European Union MRL $\left(0.1 \mathrm{mg} \mathrm{kg}^{-1}\right)$ and another six control samples were similarly prepared at half the European MRL $\left(0.05 \mathrm{mg} \mathrm{kg}^{-1}\right)$. The fortified samples were allowed to stand in the dark for $30 \mathrm{~min}$ at room temperature before starting the extraction procedure.

\section{Extraction and clean-up}

The extraction procedure that is described below for the pig and chicken matrices was carried out on the blank samples and the fortified samples as well.

Pig. To an amount of $4 \pm 0.01 \mathrm{~g}$ of previously spiked homogenate, $9 \mathrm{ml}$ of 
a $5 \%$ trichloroacetic acid (TCA) aqueous solution were added ${ }^{19}$. This mixture was thoroughly homogenized in a vortex for 1 minute. Then, the homogenate was placed in an orbital shaker at $20^{\circ} \mathrm{C}$ during 10 minutes and centrifuged at $2325 \mathrm{xg}$ for 10 minutes at $4^{\circ} \mathrm{C}$. The supernatant was saved and the pellet was extracted again following the same procedure as described in the previous paragraph. Both supernatants were charged into Oasis C-18 columns (200 $\mathrm{mg}$ ) and $6 \mathrm{ml}$ capacity previously conditioned with $6 \mathrm{ml}$ methanol and $6 \mathrm{ml}$ water and washed with $10 \mathrm{ml}$ water. Quinolones were eluted with $3 \mathrm{ml}$ of a mixture methanol-ammonia (75\%-25\%). ${ }^{11,28}$ Samples were evaporated under nitrogen stream at $35^{\circ} \mathrm{C}$ reaching almost dryness, the residue was dissolved in $600 \mu \mathrm{L}$ aqueous formic acid $(0.4 \% \mathrm{v} / \mathrm{v})$ and filtered through a $0,22 \mu \mathrm{m}$ PVDF membrane. The internal stardard was added and the samples were diluted to $1 \pm 0,01 \mathrm{~g}$ with aqueous formic acid $(0,4 \% \mathrm{v} / \mathrm{v})$ before injecting $100 \mu \mathrm{L}$ into the LC-Fl system.

Chicken. The extraction and clean-up procedure was exactly the same as the one described above for pig with only one minor change: milli-Q water (20 $\mathrm{ml}$ ) is first added to 4 grams of chicken homogenate instead of TCA. ${ }^{20,21}$

\section{Instrumentation}

The HPLC apparatus comprised a 1200 series quaternary pump and a thermally stabilized autosampler from Agilent (Santa Clara, CA, USA) equipped with a fluorescence detector and DAD and an acquisition and data analysis program "ChemStation". Chromatographic separation was achieved using an X-Terra RP-18 (3.5 $\mu \mathrm{m}, 150 \times 4.6 \mathrm{~mm})$ Waters (Milford, USA) and a Waters pre-column RP-18 $(3.5 \mu \mathrm{m}, 3.9 \times 20 \mathrm{~mm})$. The mobile phase consisted of a mixture of a $0.05 \mathrm{M}$ sodium phosphate buffer; $\mathrm{pH} 3$ (A) with acetonitrile (B). A linear gradient was run ( $82 \%$ A for $5 \mathrm{~min} ; 67 \%$ A over the next $10 \mathrm{~min}$, and finally $82 \%$ A for 3 additional $\mathrm{min}$ ) at a flow rate of $1 \mathrm{ml} / \mathrm{min}$.

Fluorescence excitation wavelength was at $\lambda_{\text {exc }} 280 \mathrm{~nm}$ and emission wavelength at $\lambda_{\mathrm{em}} 450 \mathrm{~nm}$ during the first 9 minutes of the run and at $\lambda_{\mathrm{exc}} 310$ $\mathrm{nm}$ and $\lambda_{\mathrm{em}} 360 \mathrm{~nm}$ from 9 to $27 \mathrm{~min}$.

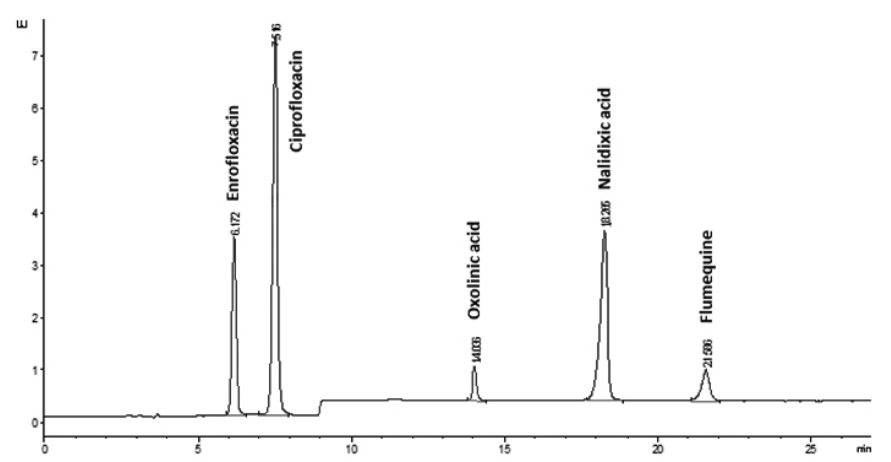

Fig 1: Chromatogram showing the retention times of quinolones in solution.

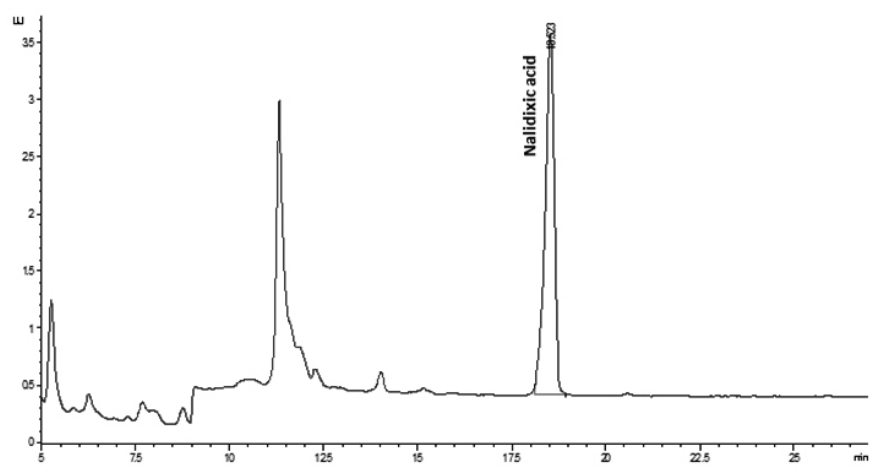

Fig 2: Chromatogram showing chicken blank with adition of nalidixic acid as internal standard

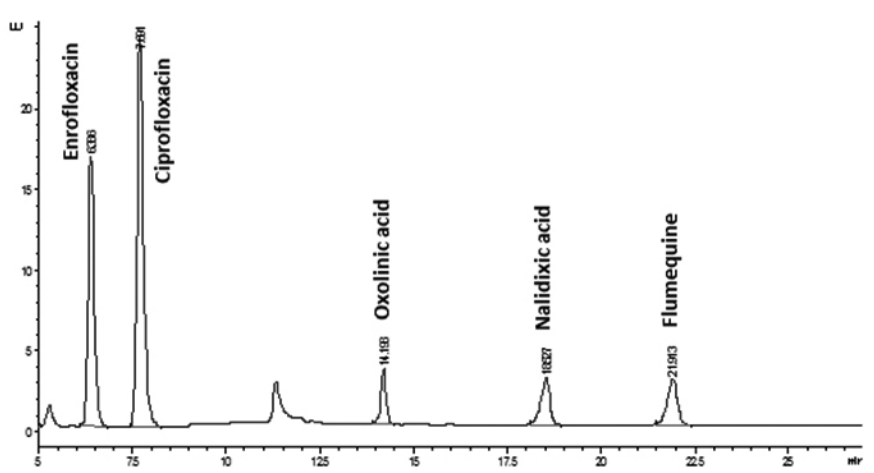

Fig 3: Chromatogram showing a chicken sample fortified to 100ppb with adition of nalidixic acid as internal standard

\section{Validation Scheme}

The simultaneous assessment of low concentrations of four quinolones in pig and chicken muscle can be performed using the LC-Fl method described in the previous section. The method validation was carried out following the requirements of the European Union guidelines EC/657/20022. This implies carrying out the complete extraction, purification and quantification procedures in three different days at sample concentrations near the MRL and at half the MRL. In each of these 3 days 26 samples were prepared: 3 blank samples (non-spiked pig and chicken homogenates); 5 calibration samples; 6 standard samples for bracketing assessment ( 2 low-; 2 medium- and 2 high-concentration standards); 6 control samples at half the MRL and 6 control samples at (or very near) the MRL.

The assignment of "blank samples" to the commercially available pig and chicken used in this study was checked chromatographically, i.e., no detectable signals were obtained at the retention times of the four studied quinolones and the internal standard.

The studied validation parameters included: Linearity of calibration curves within an appropriate range in different days; recovery of spiked samples; within-laboratory reproducibility precision; decision limit $\left(\mathrm{CC}_{\alpha}\right)$, capability of detection $\left(\mathrm{CC}_{\beta}\right)$; uncertainty; and limits of detection and quantification.

\section{RESULTS AND DISCUSSION}

\section{Calibration linearity and repeatability precision}

The calibration curves obtained on three separate days for the four quinolones under study for the spiked pig and chicken samples were linear in the concentration range $0.005-0.200 \mathrm{mg} \mathrm{kg}^{-1}$, thus including $1 / 2 \mathrm{MRL}$ and the MRL for all of them. In all cases the slopes and intercepts for each compound in each matrix were essentially the same on the three different days and the coefficients of determination were $\geq 0.989$.

Quantification of each quinolone was made using the bracketing technique once the linearity of response from concentration was verified. This technique avoids the instrumental drift errors since the sample concentration is obtained from the interpolation between low and high standard values, which bracket the sample concentration. The average values $(\mathrm{N}=6$, for each day) obtained at $1 / 2$ MRL and at the MRL together with their corresponding coefficient of variation are shown in Table 2. 
Table 2. Average values $\left(\mu \mathrm{g} \mathrm{Kg}^{-1}\right)$ and coefficients of variation of control samples at $1 / 2 \mathrm{MRL}$ and at the MRL for enrofloxacin, ciprofloxacin, oxolinic acid and flumequine in pig and chicken muscle.

\begin{tabular}{|c|c|c|c|c|c|}
\hline \multirow{3}{*}{ Analyte } & \multirow{3}{*}{ Day } & \multicolumn{2}{|c|}{$1 / 2 \mathrm{MRL}$} & \multicolumn{2}{|c|}{ MRL } \\
\hline & & Pig & Chicken & Pig & Chicken \\
\hline & & $\begin{array}{l}\text { Average }(\mathrm{CV} \%) \\
\quad\left(\mu \mathrm{g} \mathrm{kg}^{-1}\right)\end{array}$ & $\begin{array}{l}\text { Average (CV\%) } \\
\left(\mu \mathrm{g} \mathrm{kg}^{-1}\right)\end{array}$ & $\begin{array}{c}\text { Average (CV\%) } \\
\left(\mu \mathrm{g} \mathrm{kg}^{-1}\right)\end{array}$ & $\begin{array}{c}\text { Average }(\mathrm{CV} \%) \\
\left(\mu \mathrm{g} \mathrm{kg}^{-1}\right)\end{array}$ \\
\hline Enrofloxacin & $\begin{array}{l}1 \\
2 \\
3\end{array}$ & $\begin{array}{l}39.95(5.7) \\
40.71(1.8) \\
42.56(4.4)\end{array}$ & $\begin{array}{l}44.42(2.6) \\
44.10(3.5) \\
41.28(7.5)\end{array}$ & $\begin{array}{l}81.85(7.3) \\
88.62(2.2) \\
87.31(3.4)\end{array}$ & $\begin{array}{l}87.34(4.4) \\
88.96(3.1) \\
82.92(4.2)\end{array}$ \\
\hline Ciprofloxacin & $\begin{array}{l}1 \\
2 \\
3\end{array}$ & $\begin{array}{l}43.69(5.5) \\
44.73(1.1) \\
47.50(4.5)\end{array}$ & $\begin{array}{l}50.28(3.3) \\
47.19(4.2) \\
47.11(3.8)\end{array}$ & $\begin{array}{l}90.53(6.2) \\
95.33(2.5) \\
96.16(2.6)\end{array}$ & $\begin{array}{l}97.70(3.4) \\
95.90(3.3) \\
95.15(5.0)\end{array}$ \\
\hline Oxolinic Acid & $\begin{array}{l}1 \\
2 \\
3\end{array}$ & $\begin{array}{c}43.00(9.1) \\
42.18(5.6) \\
34.95(14.4)\end{array}$ & $\begin{array}{l}40.77(3.8) \\
41.35(3.5) \\
39.21(8.4)\end{array}$ & $\begin{array}{l}80.60(8.9) \\
88.99(3.3) \\
81.64(5.7)\end{array}$ & $\begin{array}{l}80.90(4.3) \\
81.51(4.4) \\
81.72(2.6)\end{array}$ \\
\hline Flumequine & $\begin{array}{l}1 \\
2 \\
3\end{array}$ & $\begin{array}{l}39.24(4.1) \\
40.21(2.1) \\
41.43(4.5)\end{array}$ & $\begin{array}{l}44.37(2.3) \\
41.87(3.8) \\
42.30(6.1)\end{array}$ & $\begin{array}{l}76.83(11.4) \\
88.10(2.0) \\
87.43(6.8)\end{array}$ & $\begin{array}{l}91.74(4.1) \\
82.81(4.7) \\
87.56(4.5)\end{array}$ \\
\hline
\end{tabular}

From the results shown in Table 2 it can be seen that the simultaneous quantification of the four quinolones under study can be conveniently accomplished by this method and that the repeatability precision $(\mathrm{CV} \%)$ is satisfactory for these low concentration values.

Within-laboratory reproducibility precision

The within-laboratory reproducibility precision $(\mathrm{N}=18)$ was evaluated by means of a $\chi^{2}$ test according to ISO $5725^{23}$. The calculated $\chi^{2}$ parameter is compared with a critical $\chi_{\text {table }}^{2}$

Each of these values is obtained from equations 1 and 2, respectively:

$$
\begin{aligned}
& \chi^{2}=\left(\frac{S_{w}}{\sigma_{w}}\right)^{2} \\
& \chi_{\text {table }}^{2}=\left[\frac{\chi_{n-1 ; 0.05}^{2}}{n-1}\right]
\end{aligned}
$$

Where $\mathrm{Sw}$ is the reproducibility standard deviation, $\sigma_{\mathrm{w}}$ is the required standard deviation and $\chi^{2}$ is the value found in a $\chi^{2}$ table for the corresponding degrees of freedom. If $\chi^{2}<\chi^{2}$ it is concluded that there is no statistical evidence that the method does not have the required precision ${ }^{23}$. Since there are no official reported requirements on an acceptable precision for this type of analysis and considering that the precision level established through the Horwitz equation ${ }^{24}$ is unacceptably high a rather stringent $\mathrm{CV}$ of $10 \%$ was selected as $\sigma_{w}$

Applying the $\chi^{2}$ test to the within-laboratory reproducibility standard deviation data for each of the four quinolones, in both edible matrices, at $1 / 2$ MRL and at the MRL concentrations the results show that in all cases the precision was as good as required.

Recovery (accuracy) tests

Since there are no certified reference materials for the quinolones in animal muscle matrices a direct accuracy or bias test cannot be performed. The accepted way for indirectly testing accuracy of a method is to perform recovery experiments on blank-spiked samples ${ }^{22}$. The average recovery $(\mathrm{R})$ is given by equation 3 :

$$
R=\frac{C_{\text {obs }}}{C_{\text {prep }}} x 100
$$

Where $\mathrm{C}_{\mathrm{obs}}$ is the average concentration found in antibiotic spiked samples and $\mathrm{C}_{\text {prep }}$ is the antibiotic concentration added to the previously measured samples. In order to evaluate the recovery, it is necessary to assess whether the $R$ value is significantly different than 1 (100\% recovery). Thus, a calculated $t$ value is compared with a critical $t$ value. The values for each of both $t$ values are obtained from equations 4 and 5 .

$$
\begin{aligned}
& t=\left[\frac{(R-1)}{u_{R}}\right] \\
& t_{c}=t_{\text {table }_{(n-1 ; 0.05)}}
\end{aligned}
$$

If $\mathrm{t}_{\text {calc }}<\mathrm{t}_{\text {crit }}$ There is no statistical evidence that $\mathrm{R}$ is different than 1 . Table 3 shows the recovery results obtained at $1 / 2$ the MRL and at the MRL concentrations on 3 separate days for the four quinolones, in pig and chicken muscle.

Table 3. Recovery of the method for the four quinolones in pig and chicken tissue

\begin{tabular}{|c|c|c|c|c|c|}
\hline \multirow{2}{*}{ Analyte } & Day & \multicolumn{2}{|c|}{ Pig } & \multicolumn{2}{c|}{ Chicken } \\
\cline { 2 - 6 } & & $\begin{array}{c}\text { \% R } \\
\text { MR }\end{array}$ & $\begin{array}{c}\text { \% R at } \\
\text { MRL }\end{array}$ & $\begin{array}{c}\text { \% R } \\
\text { MRL/2 }\end{array}$ & $\begin{array}{c}\% \mathrm{R} \\
\text { MRL }\end{array}$ \\
\hline & 1 & 102 & 95 & 103 & 102 \\
\hline Enrofloxacin & 2 & 103 & 105 & 102 & 104 \\
\hline & 3 & 98 & 102 & 95 & 96 \\
\hline & 1 & 108 & 102 & 111 & 108 \\
\hline Ciprofloxacin & 2 & 110 & 109 & 103 & 106 \\
\hline & 3 & 106 & 109 & 102 & 105 \\
\hline & 1 & 107 & 91 & 99 & 96 \\
\hline Oxolinic Acid & 2 & 104 & 102 & 97 & 97 \\
\hline & 3 & 80 & 93 & 91 & 96 \\
\hline & 1 & 97 & 87 & 98 & 103 \\
\hline Flumequine & 2 & 99 & 101 & 92 & 93 \\
\hline & 3 & 92 & 99 & 93 & 97 \\
\hline
\end{tabular}

The corresponding statistical test was made for each of the results shown in Table 3. The Recovery (R) was not significantly different than 1 in almost all of 
the cases, with only 3 exceptions, which were marginally different than 1 . Thus, it can be concluded that the indirect assessment of the accuracy of the proposed analytical method by means of recovery assays is satisfactory. Moreover, the results obtained are in line with the proposed recovery values suggested at the EU guidelines ${ }^{22}$ stating that for samples spiked at concentrations above $10 \mu \mathrm{g}$ $\mathrm{kg}^{-1}$ the recoveries of a confirmation method should range between 80 to $110 \%$.

Decision limit $\left(C C_{\alpha}\right)$ and capability of detection $\left(C C_{\beta}\right)$

The decision limit $(\mathrm{CC} \alpha)$ is defined as the limit at and above which it can be concluded with an error probability of $\alpha$ ( $1 \%$ for substances with non permitted limits and 5\% for substances with a permitted limit as the MRL) that a sample is non-compliant. On the other hand, the capacity of detection $(C C \beta)$ is defined as: the smallest content of the substance that may be detected, identified and/or quantified in a sample with an error probability of $\beta(5 \%$ for all substances with permitted or no permitted limit).

In our case, the quinolones under study have a MRL (a permitted limit). Thus, the EU guidelines ${ }^{22}$ recommend the use of equations 6 and 7 for the evaluation of $\mathrm{CC} \alpha$ and $\mathrm{CC} \beta$ :

$$
\begin{aligned}
& \mathrm{CC} \alpha=\mathrm{C}_{\mathrm{MRL}}+1.64 \mathrm{SD}_{20} \text { representative samples spiked at MRL level } \\
& \mathrm{CC} \beta=\mathrm{CC} \alpha+1.64 \mathrm{SD}_{20} \text { representative samples spiked at CC } \alpha \text { level }
\end{aligned}
$$

Where $\mathrm{C}_{\mathrm{MRL}}$ is the concentration at the MRL (or alternatively, at $1 / 2$ the MRL) and $\mathrm{SD}_{20}$ is the reproducibility standard deviation of samples spiked at the MRL level. In this study, our validation scheme (see Experimental) included 18 representative spiked samples for each of the quinolones, at $1 / 2$ MRL and at the MRL and at each of the matrices (pig and chicken muscle). The values for $C C \alpha$ and $C C \beta$ experimentally obtained for pig and chicken muscle samples are summarized in Table 4 and 5 .

Table 4. Decision limit and detection capability of four quinolones at $1 / 2$ MRL and at the MRL for pig muscle, together with the corresponding reproducibility coefficient of variation (\%).

\begin{tabular}{|c|c|c|c|c|}
\hline \multirow{2}{*}{ Analyte } & \multicolumn{2}{|c|}{$1 / 2 \mathrm{MRL}$} & \multicolumn{2}{c|}{ MRL } \\
\cline { 2 - 5 } & $\begin{array}{c}\mathrm{CC} \alpha \mu \mathrm{g} \\
\mathrm{kg}^{-1}\end{array}$ & $\mathrm{CC} \beta \mu \mathrm{kg}^{-1}$ & $\begin{array}{c}\mathrm{CC} \alpha \mu \mathrm{g} \\
\mathrm{kg}^{-1}\end{array}$ & $\begin{array}{c}\mathrm{CC} \beta \mu \mathrm{g} \\
\mathrm{kg}^{-1}\end{array}$ \\
\hline Enrofloxacin & 53.4 & 56.8 & 104.5 & 109.0 \\
\hline Ciprofloxacin & 54.3 & 58.6 & 107.6 & 115.2 \\
\hline Oxolinic Acid & 59.3 & 68.7 & 110.8 & 121.7 \\
\hline Flumequine & 52.9 & 55.8 & 113.9 & 127.8 \\
\hline
\end{tabular}

Table 5. Decision limit and detection capability of four quinolones at $1 / 2$ MRL and at the MRL for chicken muscle, together with the corresponding reproducibility coefficient of variation (\%).

\begin{tabular}{|c|c|c|c|c|}
\hline \multirow{2}{*}{ Analyte } & \multicolumn{2}{|c|}{$1 / 2 \mathrm{MRL}$} & \multicolumn{2}{c|}{ MRL } \\
\cline { 2 - 5 } & $\begin{array}{c}\mathrm{CC} \alpha \mu \mathrm{g} \\
\mathrm{kg}^{-1}\end{array}$ & $\begin{array}{c}\mathrm{CC} \beta \mu \mathrm{g} \\
\mathrm{kg}^{-1}\end{array}$ & $\mathrm{CC} \alpha \mu \mathrm{g} \mathrm{kg}^{-1}$ & $\begin{array}{c}\mathrm{CC} \beta \mu \mathrm{g} \\
\mathrm{kg}^{-1}\end{array}$ \\
\hline Enrofloxacin & 53.73 & 57.46 & 108.52 & 117.05 \\
\hline Ciprofloxacin & 53.14 & 56.27 & 108.15 & 116.30 \\
\hline Oxolinic Acid & 53.52 & 57.03 & 104.58 & 109.16 \\
\hline Flumequine & 53.53 & 57.07 & 109.84 & 119.67 \\
\hline
\end{tabular}

For all the values presented in Tables 4 and 5 the associated relative reproducibility standard deviation was less than $9 \%$.

Evaluation of the measurement uncertainty

The uncertainty is a parameter associated with the result of a measurement that characterizes the dispersion of values that could be reasonably assigned to the measurement. In this study, quantification of the analytes was made using area and concentration ratios (analyte/internal standard). When area ratios are used for the quantification process the uncertainty of the sample concentration is concisely described as follows:

$\mathrm{RC}$ is defined as the analyte/internal standard concentration ratio and RA is the corresponding peak area ratio. Therefore, the associated uncertainty is given by the combination of the uncertainties of each of those concentrations using the law of error propagation. In this way, the uncertainty of RC is obtained from equation 8 :

$$
u\left(\frac{C_{\text {low-std }}}{C_{I S}}\right)=\frac{C_{\text {low-std }}}{C_{I S}} \times \sqrt{\left(\frac{u_{C . l o w-s t d}}{C_{\text {low-std }}}\right)^{2}+\left(\frac{u_{C . I S}}{C_{I S}}\right)^{2}}
$$

On the other hand, in order to estimate the uncertainty associated with the RA values it is necessary to calculate first the ratio of analyte/internal standard areas for each measurement. Then, the uncertainties area ratios are calculated as the standard deviation of the mean value of the ratios obtained in each step divided by the square root of $n$, which is the number of measurements.

$$
u_{R A}=\frac{S D_{\overline{R A_{n}}}}{\sqrt{n}}
$$

The sample concentration uncertainty is carried out combining the standard uncertainty of the sample/internal standard concentration ratio with the standard uncertainty of the internal standard concentration. Finally, the sample concentration standard uncertainty is calculated from equation $10 .^{25}$

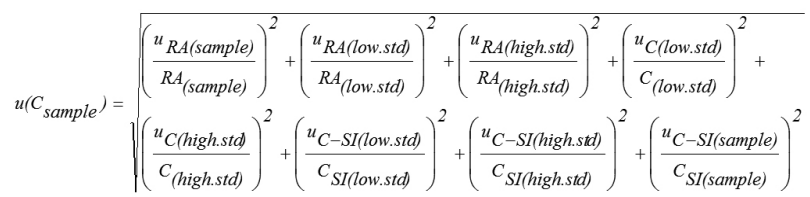

These mathematical calculations are performed using a Kragten spreadsheet $^{26}$

Table 6. Average (3-day results) relative percentage standard uncertainty values for quinolones concentrations in chicken and pig muscle at $1 / 2 \mathrm{MRL}$ and MRL values.

\begin{tabular}{|c|c|c|c|c|}
\hline \multirow{2}{*}{ Analyte } & \multicolumn{2}{|c|}{ Pig } & \multicolumn{2}{c|}{ Chicken } \\
\cline { 2 - 5 } & $\begin{array}{c}\text { RU(\%) at } 1 / 2 \\
\text { MRL }\end{array}$ & $\begin{array}{c}\text { RU(\%) at } \\
\text { MRL }\end{array}$ & $\begin{array}{c}\text { RU(\%) at } \\
1 / 2 \text { MRL }\end{array}$ & $\begin{array}{c}\text { RU(\%) at } \\
\text { MRL }\end{array}$ \\
\hline Enrofloxacin & 5.2 & 6.3 & 5.1 & 5.0 \\
\hline Ciprofloxacin & 6.6 & 6.2 & 5.7 & 6.3 \\
\hline Oxolinic acid & 10.5 & 7.2 & 6.3 & 6.3 \\
\hline Flumequine & 6.8 & 9.0 & 5.2 & 4.8 \\
\hline
\end{tabular}

Typical standard uncertainties for these analytes in pig and chicken muscle have not been reported. However, the relative percentage standard uncertainty values obtained in this study, which are shown in Table 6; appear to be satisfactory when compared with the reported uncertainties for these compounds in several other matrices. ${ }^{1,27,28}$

Evaluation of the limits of detection (LoD) and quantification (LoQ)

The limit of detection is defined as the minimum amount of substance that can be detected at a given confidence limit (usually 95\%) but not necessarily accurately quantified. It is generally reported as a concentration or amount of substance and it is derived from the smallest signal that can be detected with a reasonable certainty for a particular analytical method.

The limit of quantification is defined as the amount of analyte that can be quantitatively determined with an acceptable level of trueness and repeatability precision. It is also reported as a concentration or amount of substance.

In the present study the LoD and LoQ values were estimated from the analysis of 9 blank samples of pig and chicken muscle, assessing the standard deviation of the average signals at the retention times of each of the quinolones. The value of 3 times the corresponding standard deviation extrapolated from a calibration curve built with the signal intensity versus concentration of 5 samples fortified at different concentration levels provides an estimation of LoD.

The LoQ is obtained from the same calibration curve described in the above paragraph as 10 times the standard deviation of the average value of the blank signals. The values obtained are summarized in Table 7. 
Table 7. Limits of detection and quantification for the analyses of quinolones in pig and chicken muscle using the developed LC-Fl method.

\begin{tabular}{|c|c|c|c|c|}
\hline \multirow{2}{*}{ Analyte } & \multicolumn{2}{|c|}{ Pig } & \multicolumn{2}{c|}{ Chicken } \\
\cline { 2 - 5 } & $\begin{array}{c}\text { LoD }(\mu \mathrm{g} \\
\left.\mathrm{kg}^{-1}\right)\end{array}$ & LoQ $\left(\mu \mathrm{kg}^{-1}\right)$ & $\begin{array}{c}\text { LoD }(\mu \mathrm{g} \\
\left.\mathrm{kg}^{-1}\right)\end{array}$ & $\begin{array}{c}\text { LoQ }(\mu \mathrm{g} \\
\mathrm{kg}^{-1}\end{array}$ \\
\hline Enrofloxacin & 1.3 & 4.3 & 1.2 & 2.0 \\
\hline Ciprofloxacin & 1.1 & 3.8 & 2.7 & 5.3 \\
\hline Oxolinic Acid & 4.1 & 13.5 & 13.0 & 18.4 \\
\hline Flumequine & 2.4 & 8.0 & 13.2 & 17.0 \\
\hline
\end{tabular}

As expected, the detection and quantification limits determined for oxolinic acid and flumequine are higher than those obtained for enrofloxacine and ciprofloxacine (Table 7). This is mainly due to the fact that the latter quinolones show a smaller instrumental response at their optimal excitation and emission wavelengths than those belonging to the fluoroquinolones group. This can be seen in figures 1-3. The differences between the LoD and LoQ of oxolinic acid and flumequine in both matrices might be explained by the fact that the impurities removal procedure in the pig matrix is more efficient than the corresponding chicken matrix.

\section{CONCLUSIONS}

A LC-Fl multiresidue method was developed that is able to simultaneously identify and quantify four quinolones in pig and chicken muscle. A simple and rapid extraction and clean-up method was used for the latter matrices as compared with other methods reported in the literature ${ }^{11,29}$.

This method provides satisfactory results in terms of its working range, recovery, precision and uncertainty. Values of these latter validation parameters are comparable to those reported in the literature. ${ }^{1,27,28}$

Values of $C C \alpha$ and $C C \beta$ obtained for the four quinolones in both food matrices are very close to the MRL value with variability lower than $8 \%$; a result that indicates its reliability. In all cases the limits of detection are much lower than $1 / 2$ the MRL.

The proposed method appears to be suitable for routine analysis in field laboratories taking into account that it can be completely carried out during one working day. However, caution is recommended before implementing modifications to the experimental conditions described in this report.

\section{ACKNOWLEDGEMENTS}

This study was carried out with the support of CORFO, Chile through a grant INNOVA 07CN1312M-95

\section{REFERENCES}

1. A. Posyniak, K. Mitrowska, Bulletin Veterinary Institute in Pulawy, 52, 427-430, (2008).

2. M. Naem, K. Khan, S. Rafiq, Journal of Applied Science, 2, 373-379, (2006).

3. B. Delepine, D. Hurtaud-Pessel, P. Sanders. The Analyst, 123, 2743-2747, (1998).
4. European Medicines Agency veterinary Medicines and Inspections. EMEA/CUMP/SAGAM/184651/2005. Consultation Committee for medicinal products for veterinary use. Reflection paper on the use of fluoroquinolones in food producing animals in the European Union: Development of resistance and impact on human and animal health.

5. S. Zhao, H. Jiang, X. Li, T. Mi, C. Li, J. Shen, Journal of Agricultural Food Chemistry, 55, 3829-3834, (2007).

6. Council Regulation 37/2010 of European Communities.

7. Maximum Residue Limits (MRLs) List of Agricultural Chemicals in Foods, The Japan Food Chemical research Foundation, Ministry of Health, Labour and Welfare of Japan. http://www.m5.ws001.squarestart.ne.jp/foundation/search.html).

8. J. Hernandez-Arteseros, J. Barbosa, R. Compaño, M. Prat, Journal of Chromatography A, 945, 1-24, (2002)

9. M. Ramos, A. Aranda, E. García, T. Reuvers, H. Hooghuis, Journal of Chromatography B, 789, 373-381, (2003).

10. N. Sultana, M. Saed, N. Shafi, A. Naz, S. Naz, H. Shamdhad, Journal of the Chilean Chemical Society, 54, 358-362, (2009).

11. J. Yorke, P. Froc, Journal of Chromatography A, 882, 63-77, (2000).

12. O. Idowu, J. Peggins, Journal of Pharmaceutical and Biomedical Analysis, $35,143-153,(2004)$

13. M. Marazuela, Moreno-Bondi M., Journal of Chromatography A, 1034, 25-32, (2004).

14. B. Toussaint, G. Bordin, Janosi A., Rodriguez A., Journal of Chromatography A, 976, 195-206, (2002).

15. L. Johnston, L. Mackay, M. Craft, Journal of Chromatography A, 982, 97-109, (2002).

16. G. van Vyncht, A. Janosi, G. Bordin, G. Toussaint, E. Maghuin-Rogister, E. De Paw, A. Rodriguez, Journal of Chromatography A, 952, 121-129, (2002).

17. S. Turnispseed, J. Roybal, A. Pfenning; P. Kijak, Analytica Chimica Acta, 483, 373-386, (2003).

18. M. Schneider, D. Donoghue, Journal of Chromatography B, 780, 83-92, (2002).

19. E. Verdon, P. Couedor, B. Roudaut, P. Sandérs, Journal of AOAC International, 88, 1179-1192, (2005).

20. N. Van Hoof, K. de Wasch, L. Okerman, W. Reybroeck, S. Poelmans, H. Noppe, H. Brabander, Analytica Chimica Acta, 529, 265-272, (2005).

21. A. Stocker, U. Brinkman, Journal of Chromatography A, 1067, 15-53, (2005).

22. Commission Decision 2002/657/EC of 12 August 2002 implementing Council Directive 96/23/EC concerning the performance of analytical methods and the interpretation of results. OJ 2002, L221, 8-36.

23. ISO 5725 ( 1 to 6 ): Accuracy (trueness and precision) of measurement methods and results, (1994).

24. W. Horwitz, Analytical Chemistry, 54, 67A-76A, (1982).

25. Guías ISO GUM JCGM100: 2008, JCGM101:2008, JCGM104:2009.

26. J. Kragten, Analyst, 119, 2161-2165, (1994).

27. L. Johnston, L. Mackay, M. Croft, Journal of Chromatography A, 982, 97-102, (2002).

28. R. Galarini, L. Fiorini, F. Angelucci, G. Tovo, E. Cristofani, Journal of Chromatography A, 1216, 8158-8164, (2009).

29. A. Juan-García, G. Font, Y Pico. Electroforesis, 27, 2240-2249, (2006)- 